\title{
PREPARATION AND EVALUATTION OF SUSTAINED DOCETAXEL NANOCRYSTALS BY NANOPRECIPITATION METHOD
}

\author{
Prasad Garrepally*1, Jagadeeshwar Kolguri ${ }^{1}$, Vijaya Kumar Bontha ${ }^{1}$, Laxmisamhitha Bontha ${ }^{1}$ \\ $1,1^{*}$ Jangaon Institute of Pharmaceutical Sciences, Yeshwanthapur, Jangaon, Dist: Jangaon, Telangana \\ State,506167
}

*Corresponding Author Email: garrepallyprasad@gmail.com

\begin{abstract}
The present study was aimed at preparing and evaluating nanocrystals of docetaxel (DTX). Total sixteen nanocrystal formulations were prepared by nanoprecipitation method using tween-80, egg lecithin and plasdone C-12 as stabilizers and polylactic-co-glycolide (PLGA) as biodegradable polymer matrix in different molar ratios. Among those only four formulations were optimized based on their particle size and zeta potential values. Those optimized formulations were then characterized for their surface morphology, assay, in-vitro drug release profile, syringibility and injectability and dilution compatibility. The DTX nanocrystal formulations consist of rod and elongated cylindrical shaped crystals with a size ranging from $80 \mathrm{~nm}$ to $250 \mathrm{~nm}$. The assay was found to be in the range of $99.562 \%$ to $103.25 \%$. The zeta potential was in the range of -18.7 to $-34.6 \mathrm{mV}$. In-vitro release data was plotted for commutative \% drug release as a function of time. In-vitro release study was analyzed using various mathematical models. Initially four formulations have shown burst release and later sustained drug release profile. F-13 (PLGA) formulation showed prolonged sustained drug release for $168 \mathrm{hr}$ followed by F7 (egg lecithin) and F10 (PVP) for $96 \mathrm{hr}$ and F2 (Tween80) for $72 \mathrm{hr}$. Based on the highest regression values (R), the best fit model for F2 and F13 were zero order, for F7 it was first order and for F10 it was peppas (super case II). All the formulations were freely passed through the lowest needle size i.e., $0.45 * 13 \mathrm{~mm}$ and they exhibited different levels of redispersibility at different time intervals.
\end{abstract}

\section{KEY WORDS}

Docetaxel, tween-80, egg lecithin, poly vinyl pyrrolidine, polylactic-co-glycolide, nanocrystals and in-vitro release.

\section{INTRODUCTION}

Among all newly discovered chemical entities about $40 \%$ drugs are lipophilic and fail to reach market due to their poor water solubility. Solubility the phenomenon of dissolution of solute in solvent to give a homogenous system, is one of the important parameters to achieve desired concentration of drug in systemic circulation for desired (anticipated) pharmacological response. Low aqueous solubility is the major problem encountered with formulation development of new chemical entities as well as for the generic development. The Biopharmaceutics Classification System (BCS) has been developed to provide a scientific approach to allow for the prediction of in vivo pharmacokinetic of oral immediate release (IR) drug products. The importance of drug dissolution in the gastrointestinal tract and permeability across the gut wall barrier in the oral absorption process has been well known since 1960s. It provides very clear and easily applied rules in determining the rate- limiting factor in the gastrointestinal drug absorption process. Solubility also plays a major role for other dosage forms like parenteral formulations as well. Solubility is one of the important parameters to achieve desired concentration of drug in systemic circulation for achieving required pharmacological response. Poorly water-soluble drugs often require high doses in order to reach therapeutic plasma concentrations. Most of the drugs are either 
weakly acidic or weakly basic having poor aqueous solubility. More than 40\% NCEs (new chemical entities) developed in pharmaceutical industry are practically insoluble in water. These poorly water-soluble drugs having slow drug absorption leads to inadequate and variable bioavailability and gastrointestinal mucosal toxicity. Problem of solubility is a major challenge for formulation scientist. The improvement of drug solubility thereby its oral bioavailability remains one of the most challenging aspects of drug development process especially for oral-drug delivery system. There are numerous approaches available and reported in literature to enhance the solubility of poorly watersoluble drugs. The techniques are chosen on the basis of certain aspects such as properties of drug under consideration, nature of excipients to be selected, and nature of intended dosage form. Especially for class II (low solubility and high permeability) substances according to the BCS, the bioavailability may be enhanced by increasing the solubility and dissolution rate of the drug in the gastrointestinal fluids. The negative effect of compounds with low solubility include poor absorption and bioavailability, insufficient solubility for IV dosing, development challenges leading to increasing the development cost and time, burden shifted to burden shifted to patient (frequent high-dose administration). There are various techniques available to improve the solubility of hydrophobic drugs. Some traditional and novel approaches to improve the solubility are particle size reduction, solid dispersion, supercritical fluid technology, cryogenic technology, inclusion complex formation techniques and nanosuspensions. Nanosuspension is biphasic systems consisting of nano sized drug particles stabilized by surfactants for either oral and topical use or parenteral and pulmonary administration. The particle size distribution of the solid particles in nanosuspensions is usually less than one micron with an average particle size ranging between 200 and $600 \mathrm{~nm}$. There are various methods for preparation of nanosuspension include Media Milling (Nanocrystals), High Pressure Homogenization in water (Dissocubes), High Pressure Homogenization in nonaqueous media (Nanopure) and combination of Precipitation and High-Pressure Homogenization (Nanoedege). Drug nanocrystals are crystals with a size in the nanometer range, which means they are nanoparticles with a crystalline character. There are discussions about the definition of a nanoparticle, which means the size of a particle to be classified as a nanoparticle, depending on the discipline, eg, in colloid chemistry particles are only considered as nanoparticles when they are in size below $100 \mathrm{~nm}$ or even below $20 \mathrm{~nm}$. Based on the size unit, in the pharmaceutical area nanoparticles should be defined as having a size between a few nanometers and $1000 \mathrm{~nm}$ $(=1 \mu \mathrm{m})$; microparticles therefore possess a size of 1$1000 \mu \mathrm{m}$. A further characteristic is that drug nanocrystals are composed of $100 \%$ drug; there is no carrier material as in polymeric nanoparticles. Dispersion of drug nanocrystals in liquid media leads to so called "nanosuspensions" (in contrast to "microsuspensions" or "macrosuspensions"). In general, the dispersed particles need to be stabilized, such as by surfactants or polymeric stabilizers. Dispersion media can be water, aqueous solutions or nonaqueous media (eg, liquid polyethylene glycol [PEG], oils). Properties of nanocrystals are size below 1 $\mu \mathrm{m}, 100 \%$ drug, no carrier, generally needed to be stabilized, crystalline or amorphous structure, increase of dissolution velocity, increase in saturation solubility, amorphous particle state offers advantages. The main reasons for the increased dissolution velocity by surface area enlargement and thus increased bioavailability. 


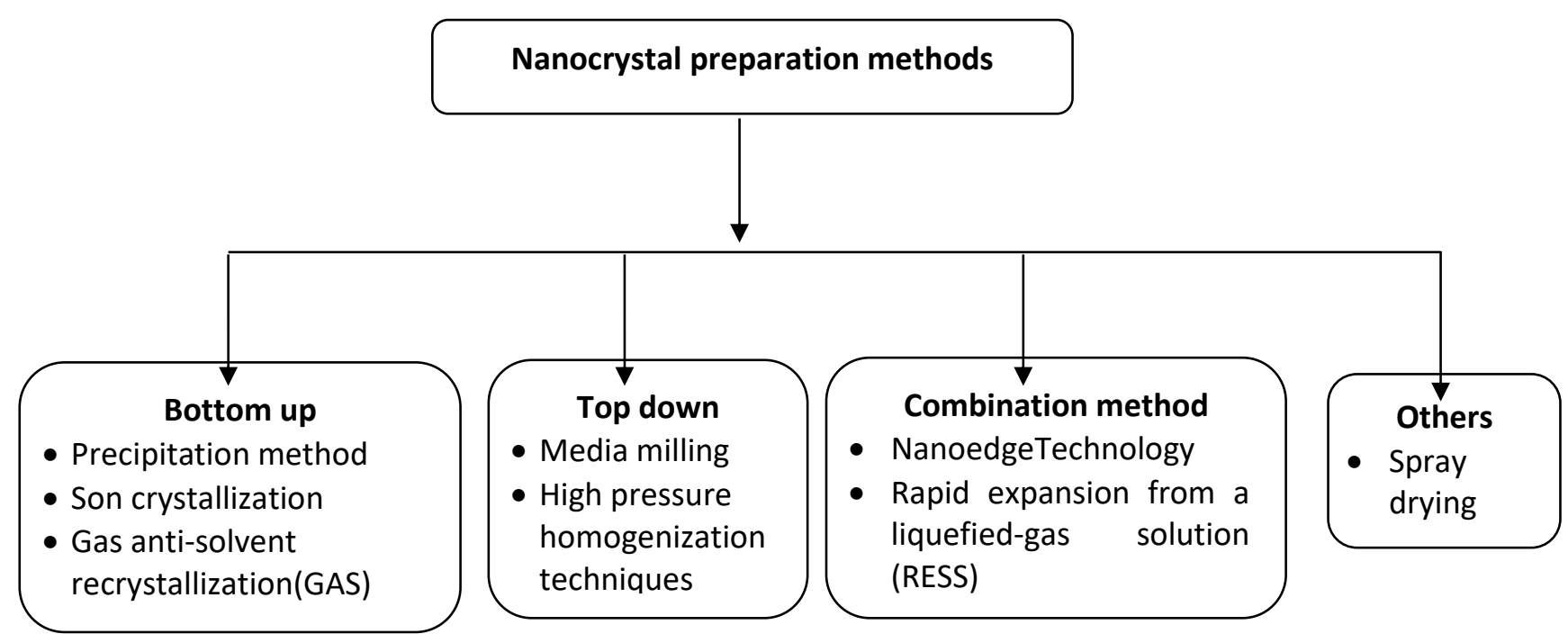

Advantages of nanocrystal are increased rate of absorption, increased bioavailability, rapid effect, improved dose proportionality, reduction in required dose, applicability to all routes of administration, nanocrystals can be administered via oral routes such as tablets, capsules, sachets or powder; preferably in the form of a tablet. Nanosuspensions can also be administered via the intravenous route due to very small particle size, and in this way, bioavailability can reach $100 \%$, reduction in fed/fasted variability, rapid, simple and cheap formulation development, possibility of high amounts (30-40 \%) of drug loading, increased reliability, sustained crystal structure-nanocrystal technology leads to an increase in dissolution rate depending on the increase in surface area obtained by reduction of the particle size of the active drug substance down to the nano size range preserving the crystal morphology of the drug, improved stability. They are stable systems because of the use of a stabilizer that prevents reaggregation of active drug substances during preparation. Suspension of drug nanocrystals in liquid can be stabilized by adding surface active substances or polymers. Applicability to all poorly soluble drugs because all these drugs could be directly disintegrated into nanometer-sized particles.

The purpose of current research work was to prepare and evaluate the sustained docetaxel nanocrystals by nanoprecipitation method for enhancement of solubility their by the bioavailability.

\section{MATERIALS AND METHODS:}

Docetaxel is a gift sample from Ningbo samreal chemicals Co., Ltd., China, Egg lecithin, Polysorbate-80 (tween-80), PVP (Plasdone C-12), Poly (Lactide-coglcolide) acid, Purac biochem, Netherlands, Purac biochem, Netherlands, ethanol, Dichloromethane, Propylene glycol, N- Methyl Pyrrolide, n- Hexane, Oleyl alcohol, Sodium hydroxide and Potassium dihydrogen are from SD fine chemicals are AR grade. The preformulation studies with the lansoprazole obtained were performed using conventional and reported techniques. The UV-Visible spectrum, solubility, flow properties, drug crystallinity were determined.

\section{PREFORMULATION STUDIES}

Characterization of Docetaxel: The drug was stored in a well closed container and protected from light. It was characterized according to the USP monograph for description, solubility, $\mathrm{pH}$ of solution and melting point. Drug solubility: Drug solubility in different solvents estimated by dissolving the drug in solvents at saturate level and mixed for $24 \mathrm{hrs}$ using shaker. After that the drug solution was filtered using $0.2 \mu \mathrm{m}$ filter and the drug concentration in the solution estimated by spectrophotometrically at $229 \mathrm{~nm}$.

Drug excipient compatibility studies: Drug - stabilizer (PVP) and the pure drug were subjected to the Fourier transform infrared spectroscopy (FT- IR) in order to check the possible drug-stabilizer interactions. 
Formulation of docetaxel parenteral nanocrystals by nano-precipitation method:

In this method, the drug was dissolved in solvent i.e., ethanol. After the drug, dissolved stabilizer solution was added. This solution was mixed using cyclomixer at 150 rpm. To this solution an Anti-solvent i.e., propylene glycol was added and mixed. The resulting formulation was kept a side for $24 \mathrm{hrs}$ at room temperature. During optimization of a formula, the volume of solvent, antisolvent and the concentration of stabilizer were considered in order to keep the formulation stable and that the final concentration of drug in the formulation is equivalent to the innovator product. The volume of solvent and anti-solvent was fixed in the all formulations by changing stabilizer concentration to a total volume of $2 \mathrm{ml}$. In all the formulations, the drug and stabilizer were taken in the molar ratios. Docetaxel nanocrystals were prepared by using tween-80. The optimized nanocrystals of docetaxel were evaluated and characterized for particle size, zeta potential, in vitro drug release and shape by SEM. Docetaxel nanocrystals were prepared by using egg lecithin. The optimized nanocrystals of docetaxel were evaluated and characterized for particle size, zeta potential, in vitro drug release and shape by SEM. Docetaxel nanocrystals were prepared by using PVP. The optimized nanocrystals of docetaxel were evaluated and characterized for particle size, zeta potential, in vitro drug release and shape by SEM. Docetaxel nanocrystals were prepared by using tween-80 and PLGA. The optimized nanocrystals of docetaxel were evaluated and characterized for particle size, zeta potential, in vitro drug release and shape by SEM.

\section{CHARACTERIZATION AND EVALUATION OF DOCETAXEL NANOCRYSTAL FORMULATIONS}

Microscopic evaluation: Placed a drop of the formulation in the middle of a clean slide and place a cover slip. Then place the prepared slide onto the stage of the microscope. Observe the shape of crystals under microscope using 40x eyepiece and capture the images by using Motic image software.

Particle size and size distribution: The Particle size can be determined by measuring the random changes in the intensity of light scattered from a suspension. Small particles in suspension undergo random thermal motion known as Brownian motion. This random motion is measured to calculate particle size. The average diameter and poly dispersity index (PDI) of the nanocrystals were determined by particle size analyzer (Horiba, nanopartica sz-100 series). $1 \mathrm{~mL}$ of the sample was diluted to $10 \mathrm{ml}$ with water and $5 \mathrm{ml}$ of solution was transferred to cuvette and measured the particle size. Stokes-Einstein equation is used to calculate the particle size.

$$
D_{h}=K_{B} T / 3 \pi \eta D t
$$

Where:

$D_{h}=$ the hydrodynamic diameter

$D t=$ the translational diffusion coefficient

$\mathrm{k}_{\mathrm{B}}=$ Boltzmann's constant

$T=$ temperature

$\eta=$ dynamic viscosity

Zeta potential: Zeta potential is a measure of the charge on a particle surface in a specific liquid medium. This value of surface charge is useful for understanding and predicting interactions between particles in suspension. Zeta potential is measured using the technique of electrophoretic light scattering where particle motion is detected in an applied electric field. The charge on the surface of a particle influences the ionic environment in the region close to the particle surface. This ionic environment is typically described using a double layer model-the A zeta potential, measure the effect of electrostatic charges; this is the basic force that causes the repulse between adjacent particles. Net results are attraction or repulsion depends upon the magnitude of both forces. The thumb rule describes the relation between zeta potential determination responses of the suspension being tested, particularly hydrophobic colloids. Zeta potential was estimated using the zetasizer (Horiba, nanopartica SZ-100 series).

Zeta potentials is calculated based on Smoluchowski equation

$$
\begin{aligned}
& \zeta=\frac{4 \pi \eta}{\varepsilon} * U * 300 * 300 * 1000 \\
& U=\alpha /[\mathrm{V} / \mathrm{L}]
\end{aligned}
$$

Where

$\zeta=$ Zeta potential

$\eta=$ Viscosity of solution

$\varepsilon=$ Dielectric constant

$\mathrm{U}=$ Electrophoretic mobility

$\alpha=$ Speed of the particle $(\mathrm{cm} / \mathrm{sec})$

$\mathrm{V}=$ Voltage and $\mathrm{L}=$ Distance of electrode 
Shape and surface morphology: Shape and surface morphology of nanoparticles was done by Scanning Electron Microscopy. The three-dimensional information about macro $(0.1-10 \mathrm{~mm})$ meso $(1-100 \mu \mathrm{m})$ and microstructure $(10-1000 \mathrm{~nm})$, is often found within the same micrograph. SEM has been used to determine particle size distribution, surface topography, texture and to examine the morphology of fractured surface. Small volume of nanoparticulate suspension was placed on an electron microscope brass stub. The stubs were placed briefly in a drier and then coated with gold in an ion sputter. Pictures of nanoparticles were taken by random scanning of the stub. The shape and surface morphology of the nanoparticles was determined from the photomicrographs of each batch.

In vitro drug release study: Optimization of Dissolution Media-Weighed quantities of drug was added to $300 \mathrm{ml}$ of Phosphate Buffered Saline 7.4 and with PBS with different concentrations of Polysorbate 80 and stirred for 30 minutes and allowed to stand for 24 hours at room temperature. After 24 hour, the suspensions filtered and absorbance of the solution measured at absorption maxima.

Membrane diffusion drug release study: The in vitro release of formulations carried out by membrane diffusion technique using dialysis sack of Molecular weight cutoff 1000 . Membrane was soaked in water for 30 minutes to remove traces of preservative and tied to one end of the glass test tube which constituted donor compartment. $2 \mathrm{ml}$ of the formulation was transferred to donor compartment and placed into receptor compartment of $400 \mathrm{ml}$ of Phosphate buffered saline Buffer $\mathrm{pH}$ with tween-80 maintained at a temperature of $37^{\circ} \mathrm{C}$ and rotated at $300 \mathrm{rpm}$ using a magnetic stir bar. At specified time points the samples were withdrawn buffer was removed and replaced with fresh buffer immediately after sampling. These samples were filtered through $0.45 \mu \mathrm{m}$ membrane filter and analyzed spectrophotometrically at $231 \mathrm{~nm}$ after suitable dilution if necessary, using appropriate blank.

Predicting mechanism of drug release: Various models were tested for explaining the kinetics of drug release.
To analyze the mechanism of the release rate kinetics of the dosage form, the obtained data fitted in to zero order, first order, Higuchi and Korsmeyer-Peppas release model, to study the drug release from the dosage form.

Zero order release rate kinetics: To study zero order release kinetics the release data are fitted to the following equation.

\section{$F=K_{0} . t$}

Where

$\mathrm{F}=$ the drug release

$\mathrm{K}_{0}=$ the release rate constant and ${ }^{\prime} \mathrm{t}$ ' is the release time The plot of \% drug release versus time is linear.

First order release rate kinetics: To study first - order release kinetics the release data are fitted to the following equation:

$\log (\mathbf{1 0 0}-\mathbf{F})=\mathbf{k t}$

The plot of log \% drug release versus time is linear.

Higuchi's release model:To study the first -order release kinetics the release data are fitted to the following equation.

$\mathbf{F}=\mathbf{k} 1 \cdot \mathbf{t}^{1 / 2}$

Where ' $k 1$ ' is the higuchi constant

In higuchi model, a plot of \% release versus square root of time is linear.

Korsmeyer and peppas release model: To study the first-order release kinetics the release data are fitted to the following equation.

$\mathbf{M}_{\mathrm{t}} / \mathbf{M}_{\boldsymbol{\alpha}}=\mathbf{K t}^{\mathrm{n}}$

Where

$M_{t} / M_{\alpha}$ is the fraction of drug released

' $\mathrm{k}$ ' is the release constant

' $\mathrm{t}$; is the release time and ' $\mathrm{n}$ ' is the diffusion constant If $n=0.89$ the release is zero order

If $n=0.475$ the release is best explained by Fickian diffusion and

If ' $n$ ' is $0.45<n<0.89$ then the release through anomalous diffusion or non-fickian diffusion (swellable and Cylindrical matrix)

In this model, a plot of $\log \left(M_{t} / M_{\alpha}\right)$ versus log (time) is linear 
Table 1: The release data of optimized nanocrystal formulations were fitted to zero order, first order, Higuchi and korsmeyer-peppas model to study the kinetics of the drug release.

\begin{tabular}{|c|c|c|c|}
\hline Model & Equation & Plot of graph & Parameters \\
\hline Zero order & $\mathrm{F}=\mathrm{K}_{0 . \mathrm{t}}$ & $\begin{array}{l}\% \text { of drug release } \\
\text { versus time }\end{array}$ & K0-release rate constant \\
\hline First order & $\begin{array}{l}\log (100-F) \\
=k t\end{array}$ & $\begin{array}{l}\text { Log } \% \text { drug release } \\
\text { versus time }\end{array}$ & $\mathrm{K}$-release rate constant \\
\hline Higuchi release & $F=k 1 \cdot t^{1 / 2}$ & $\begin{array}{l}\% \text { drug release } \\
\text { versus square root } \\
\text { time }\end{array}$ & K1'higuchi constant \\
\hline $\begin{array}{l}\text { Korsmeyer and } \\
\text { peppas release }\end{array}$ & $\begin{array}{l}\mathrm{M}_{\mathrm{t}} / \mathrm{M}_{\alpha}= \\
\mathrm{Kt}^{\mathrm{n}}\end{array}$ & $\log (\mathrm{Mt} / \mathrm{M \alpha})$ & $\begin{array}{l}\mathbf{M}_{\mathbf{t}} / \mathbf{M}_{\boldsymbol{\alpha}} \text { - fraction of drug released K-release rate } \\
\text { constant } \mathrm{n} \text { "exponent characterising diffusional } \\
\text { mechanism }\end{array}$ \\
\hline \multicolumn{4}{|c|}{$n$ *-The value of $n$ determines the drug release mechanism } \\
\hline & \multicolumn{3}{|c|}{ Table 02: Prediction of drug release mechanism } \\
\hline & \multicolumn{2}{|c|}{ Diffusional exponent(n) } & Drug release mechanism \\
\hline & \multicolumn{2}{|l|}{$<0.43$} & Fickian diffusion \\
\hline & \multicolumn{2}{|l|}{$0.43-0.85$} & Anomalous(non-fickian) transport \\
\hline & \multicolumn{2}{|l|}{$0.85-1$} & Case II transport \\
\hline & \multicolumn{2}{|l|}{$>1$} & Supercase II transport \\
\hline
\end{tabular}

\section{RESULTS AND DISCUSSION}

The solubility of pure drug in different solvents was carried out by dissolving the drug at saturated levels and it reveals that the drug is completely insoluble in water and propylene glycol, slightly soluble in poly ethylene glycol, soluble in dichloromethane, ethanol, n-methyl pyrrolidone and isopropyl alcohol. From the results, it was observed that highest solubility of docetaxel was observed in dichloromethane, followed by NMP, ethanol, isopropyl alcohol, polyethylene glycol, propylene glycol and very least was found in water. Among the solvents ethanol was selected by considering its safety compared to the other solvents, solubility of drug and listed in FDA inactive ingredient guide at $49.7 \%$ usage for intravenous administration. From the I.R. spectral analysis it was found that I.R. spectrum of docetaxel with PVP 1:100 ratio showed all characteristic peaks in combination with no significant changes as shown in figure 1 and Table 3 . The absorption spectrum of pure drug was scanned between 200-400 nm with 100, 50, 25, $12.5 \mu \mathrm{g} / \mathrm{mL}$ concentration prepared in isopropyl alcohol. Docetaxel exhibits absorption peaks, at $229 \mathrm{~nm}$ and the other at $203 \mathrm{~nm}$. The maximum absorbance is observed at 229 $\mathrm{nm}$. Selection of the solvent and anti-solvent for formulation development is based on the solubility studies and published literature.

Table 03: Compatibility stretching of Docetaxel and Docetaxel +PVP

\begin{tabular}{lll}
\hline Functional Group & Docetaxel & Docetaxel +PVP \\
\hline O-H bending & 3378.16 & 3375.39 \\
C-H Stretch & $2984.39,2931.59$ & $2980.71,2921.93$ \\
C=O stretch & 1710.63 & 1711.85 \\
C-H rock (alkane) & 1365.62 & 1367.91 \\
C-H rock (long chain) Alkanes & 745 & 748.12 \\
Aromatic C-H out of plane bending & 708.53 & 709.61 \\
\hline
\end{tabular}




\section{Spectra Comparison}

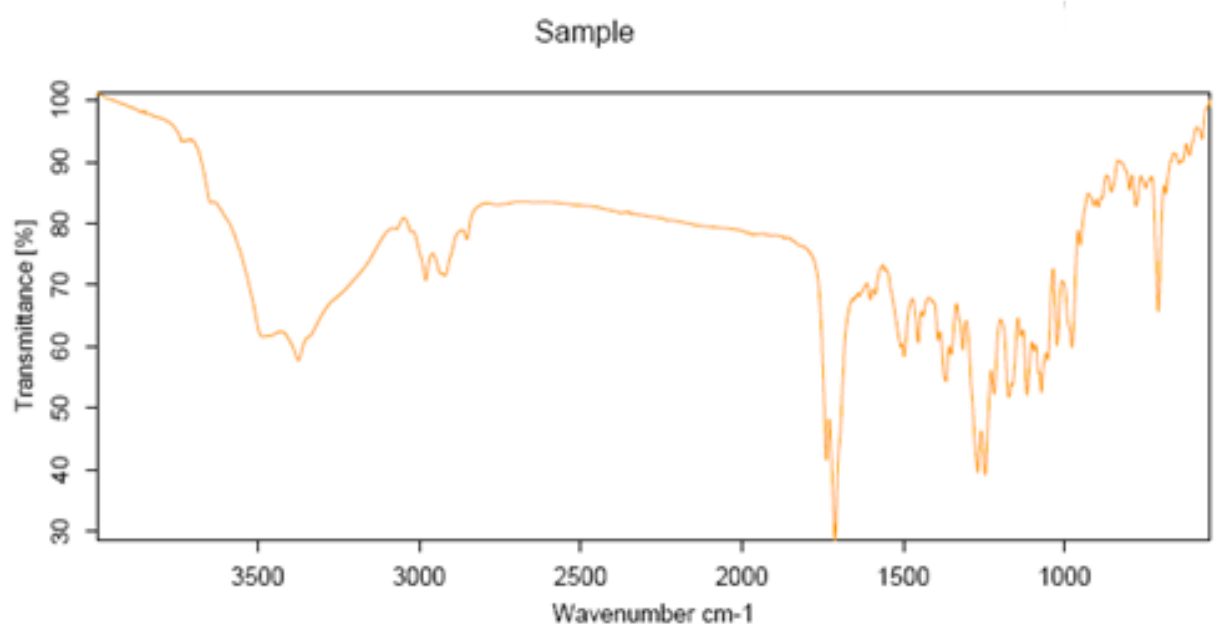

Reference

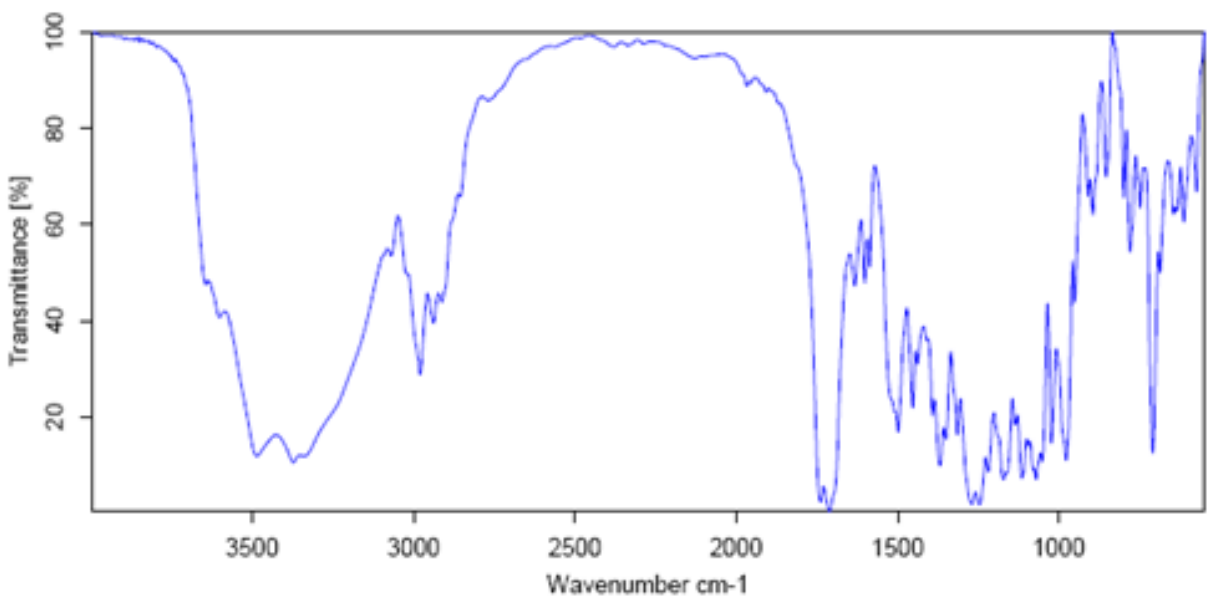

Result: OK A

Correlation: $90.05 \%$

Threshold: $98.00 \%$

Sample: Docetaxel PVP.0

Compared with Reference: Docetaxel Drug05.0

Figure 01: IR spectra of Doectaxel and Physical mixture (Doectaxl +PVP)

Different shaped crystals were observed in all the formulations as given in the table. In case of F14, F15 and F16 as the polymer concentration increases, the clarity of formulations was decreased, because of the increase in viscosity due to its high molecular weight.
Upon standing the sediment was formed in those formulations so that they said to be physically unstable. From the above results, it was observed that the shape and size of the crystals was changed with the type and concentration of stabilizer. 


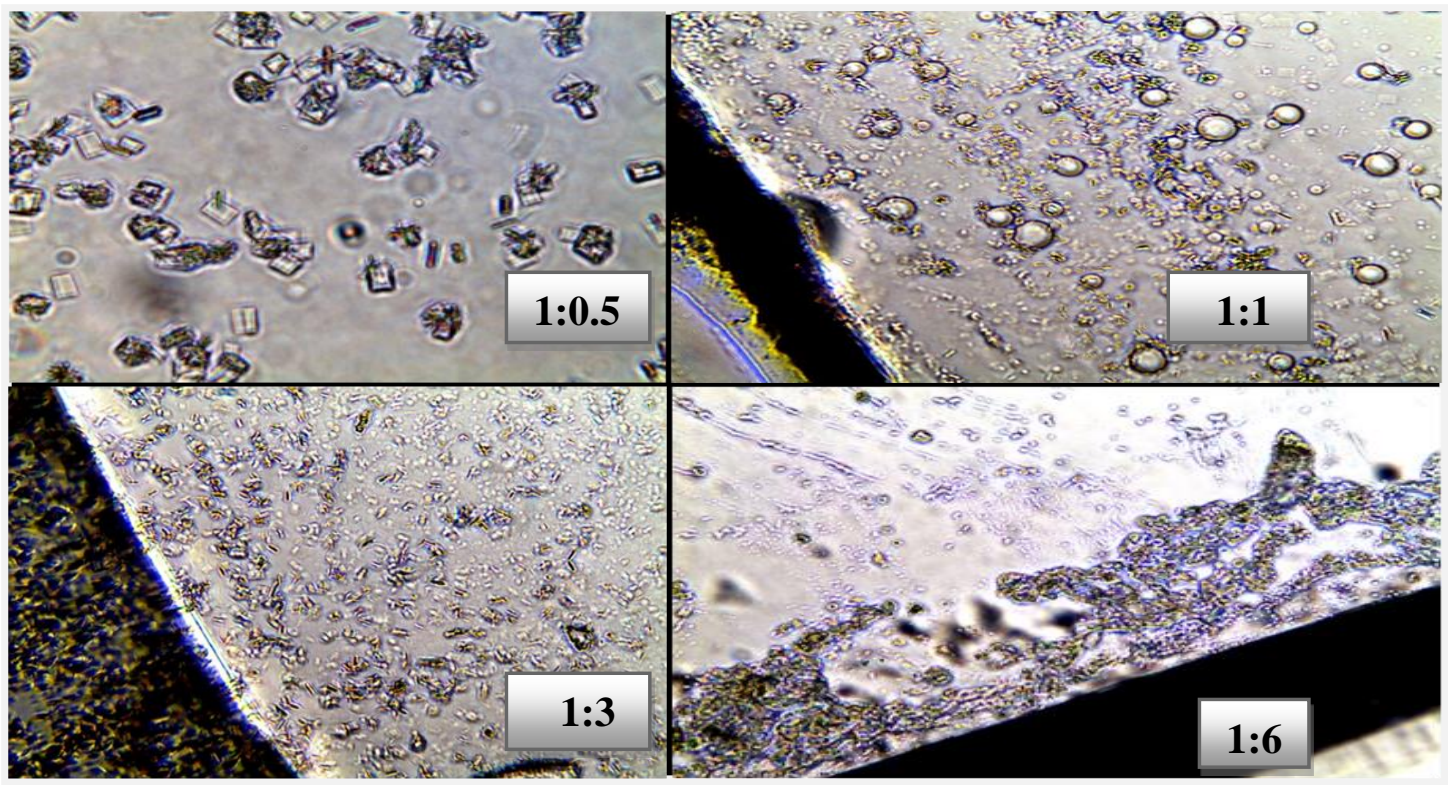

Fig-6: MICROSCOPIC IMAGES OF TWEEN 80 FORMULATIONS

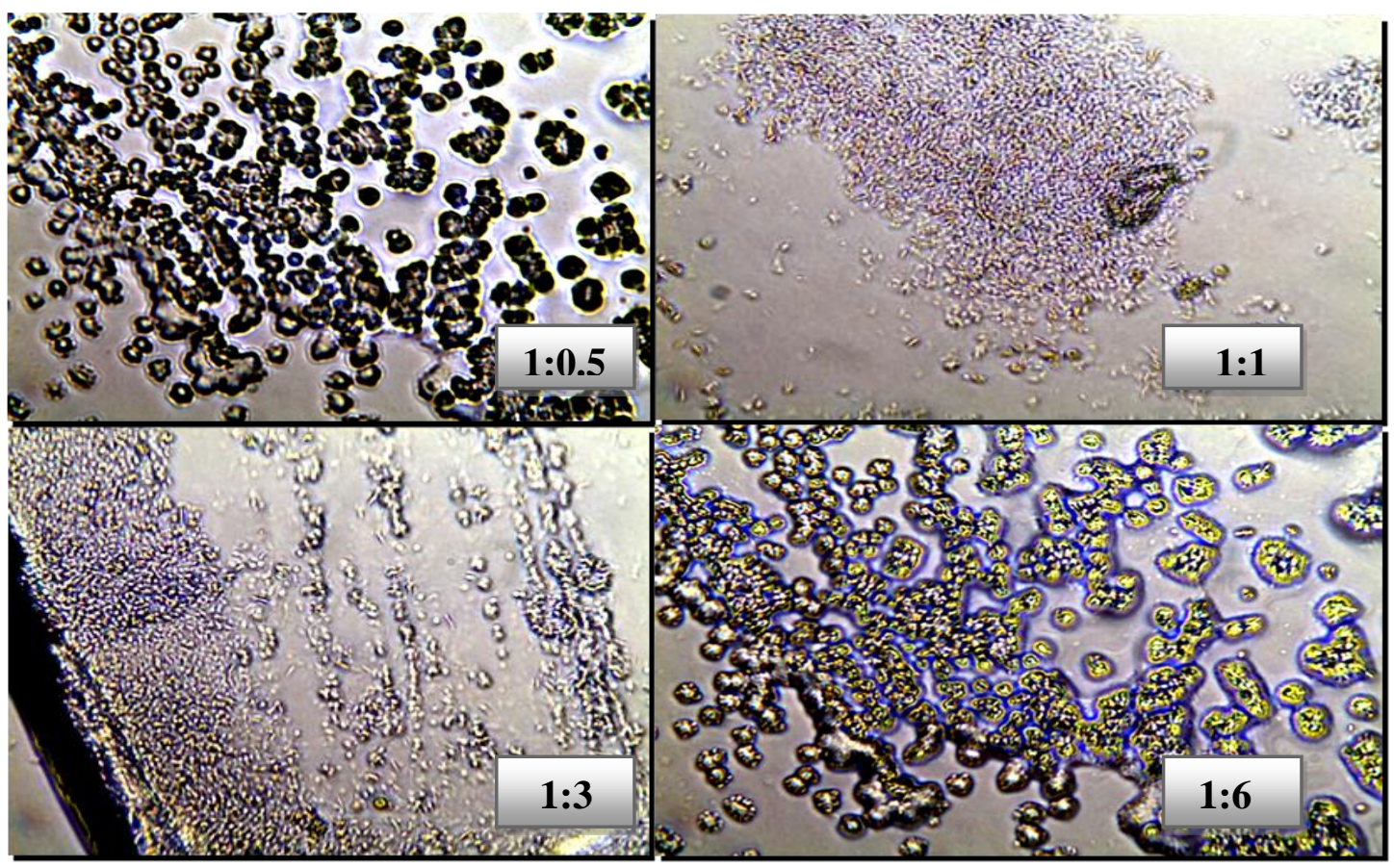

Fig.-7: MICROSCOPIC IMAGES OF EGG LECITHIN FORMULATIONS 


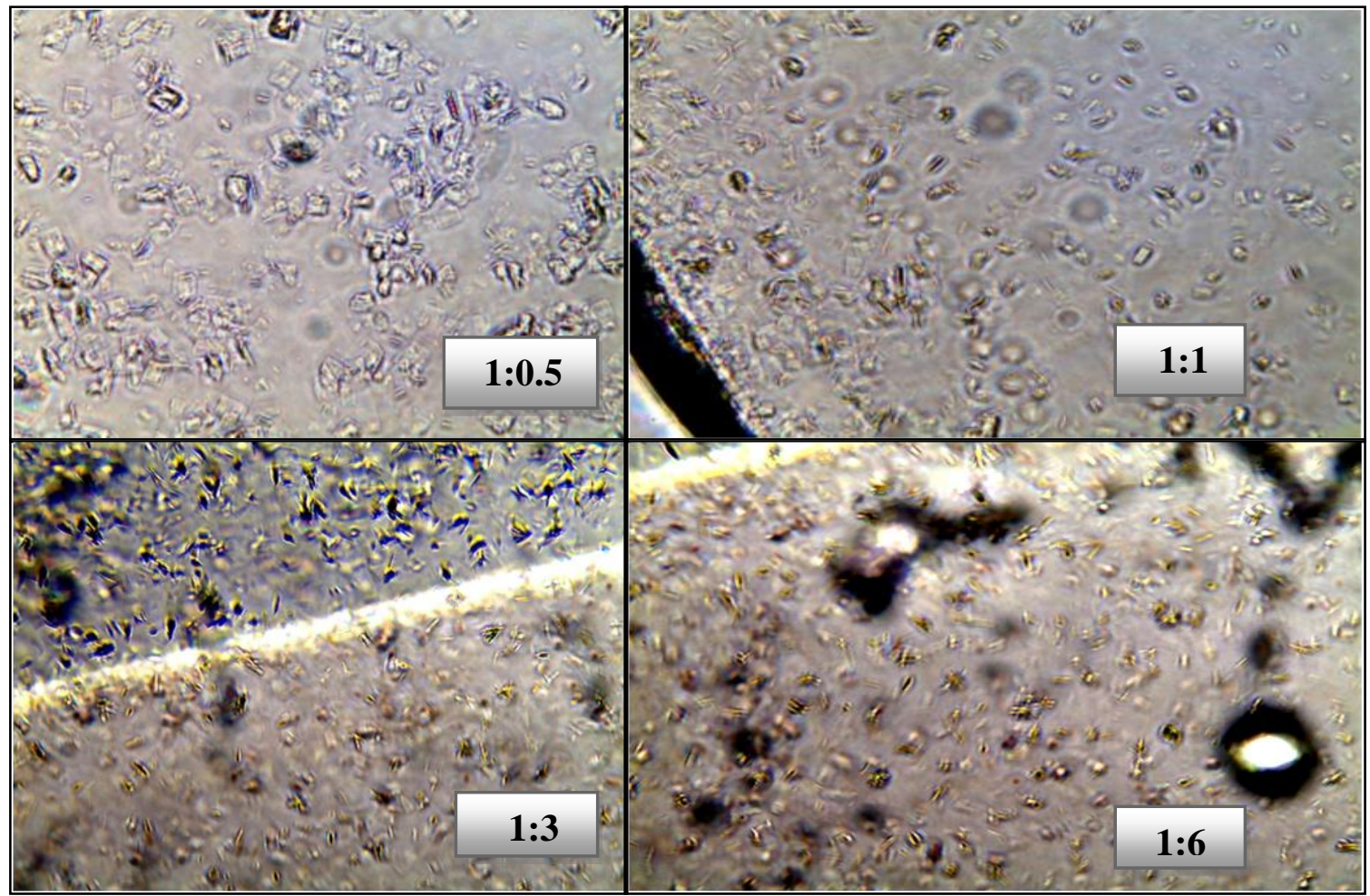

Fig.-8: MICROSCOPIC IMAGES OF PVP FORMULATIONS

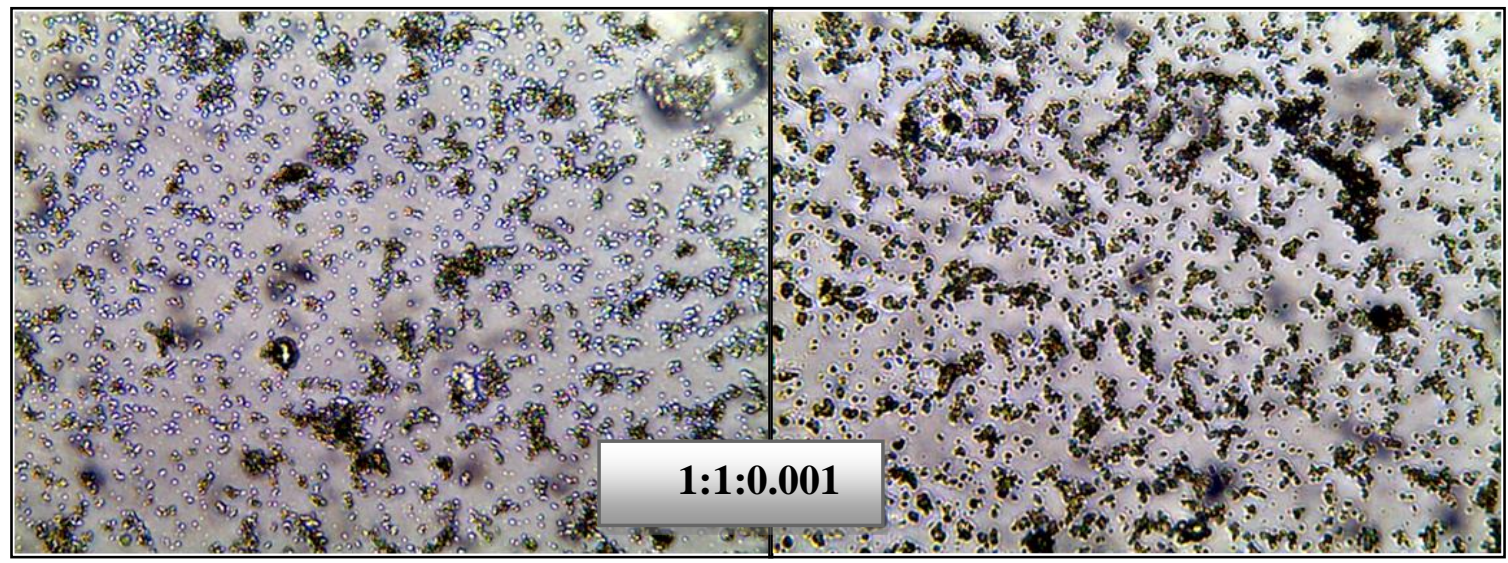

Fig.-9: MICROSCOPIC IMAGES OF PLGA FORMULATIONS

\section{PARTICLE SIZE DISTRIBUTION}

Particle size of all formulations was found in the nanometer range. The results of particle size data are shown in Table -5, 6, 7 and 8 in Fig.- 10,11,12.

Table-5: Experiment -II: Tween 80 formulations

\begin{tabular}{lllll}
\hline \multirow{2}{*}{ Particle size } & \multicolumn{3}{l}{ Molar Ratio } \\
\cline { 2 - 5 } & $\mathbf{1 : 0 . 5 [ F 1 ]}$ & $\mathbf{1 : 1 [ F 2 ]}$ & $\mathbf{1 : 3 [ F 3 ]}$ & $\mathbf{1 : 6 [ F 4 ] ~}$ \\
\hline D $_{10}$ & 194.6 & 118.1 & 52.2 & 120.3 \\
D $_{50}$ & 268 & 144.2 & 190 & 137.5 \\
D90 $_{\text {Mean Diameter }}$ & 257.4 & 178.7 & 173 & 142.4 \\
PDI & $\mathbf{2 4 0 n m}$ & $\mathbf{1 4 2 . 9 n m}$ & $\mathbf{1 3 8 . 4}$ & $\mathbf{1 3 3 . 4 n m}$ \\
\hline
\end{tabular}




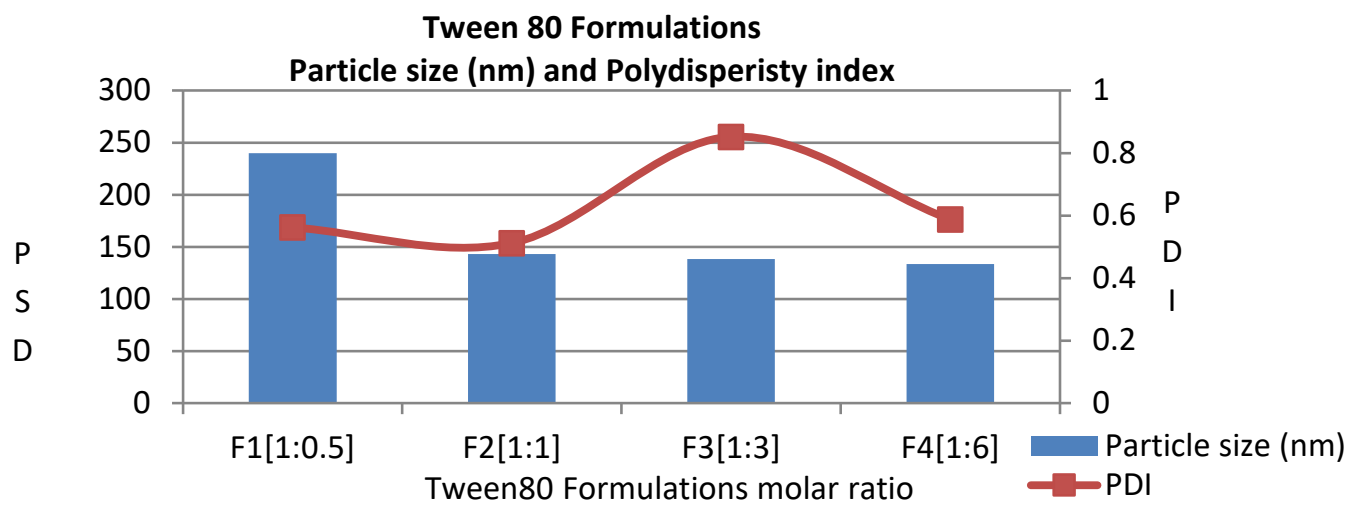

Fig. 10: Tween 80 Formulations Particle size $(\mathrm{nm})$ and Polydisperisty index

\section{CONCLUSION:}

All the formulations consist of nanosized paricles, the average size and polydispersity index of nanocrystals were given in the table. The size of docetaxel nanocrystals in this study were ranged between 133.4 to $240 \pm 22.2 \mathrm{~nm}$.the particle size of four molar ratios found to be in the fallowing order: F1 [1:0.5] >F2 [1:1]>
F3 [1:3]> F4 [1:6]. From f1 to $f 2$ there was a greater decrease in particle size but in case of $\mathrm{f} 3$ and $\mathrm{f} 4$ it was a slight decrese in paricle size and the size was almost nearer to the $\mathrm{f} 2$ formulation. From this observation, it can be concluded that after 1:1 molar ratio, upon increasing the tween 80 concentration there was no greater decrease in the particle size so, there was no use of furthur increasing stabilizer concentration.

Table-6: Experiment -III: Egg lecithin formulations

Particle size of all formulations was found in the nanometer range. The results of particle size data are shown in Table-6.

\begin{tabular}{lllll}
\hline \multirow{2}{*}{ Particle size } & \multicolumn{4}{l}{ Molar ratios } \\
\cline { 2 - 5 } & $\mathbf{1 : 0 . 5 [ F 5 ]}$ & $\mathbf{1 : 1 [ F 6 ]}$ & $\mathbf{1 : 3 [ F 7 ] ~}$ & $\mathbf{1 : 6 [ F 8 ] ~}$ \\
\hline D $_{10}$ & 256 & 255.1 & 154.2 & 595.6 \\
D $_{50}$ & 473.2 & 287.8 & 172 & 663.3 \\
D90 $_{90}$ & 310.3 & 326.4 & 198.2 & 311.3 \\
Mean Diameter & $\mathbf{3 4 6 . 5}$ & $\mathbf{2 8 9 . 1} \mathbf{n m}$ & $\mathbf{1 7 4 . 8 n m}$ & $\mathbf{5 2 3 . 4 n m}$ \\
PDI & $\mathbf{0 . 7 5 6}$ & $\mathbf{0 . 5 4 2}$ & $\mathbf{0 . 4 8 9}$ & $\mathbf{0 . 6 5 5}$ \\
\hline
\end{tabular}

Egg lecithin Formulations

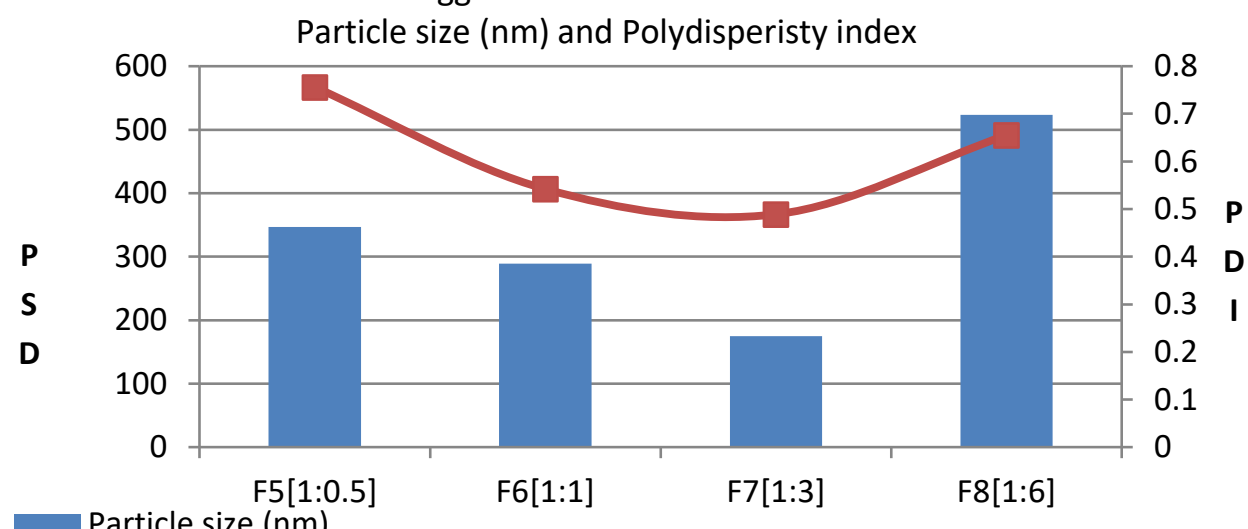

egg lecithin Formulations molar ratio

Fig. 11: Egg lecithin Formulations Particle size ( $\mathrm{nm})$ and Polydisperisty index 


\section{Conclusion:}

All the formulations consist of nanosized paricles, the average size and polydispersity index of nanocrystals were given in tha table. The size of docetaxel nanocrystals in this study were ranged between 523.4 to $174.8 \pm 24.3 \mathrm{~nm}$.the particle size of four molar ratios found to be in the fallowing order: F8 [1:6] >F5 [1:0.5]> $F 6$ [1:1]> F7 [1:3]. From f5 to $f 7$ there was a greater decrease in particle size but in case of $f 6$, the particle size was again increased this is because, we believe our nanocrystals are in a meta-stable state stabilized by surface adsorbed egg lecithin surfactant. At low concentration of egg lecithin, monomers bind with high affinity to the crystal surface. At high concentration, monomers aggregated and bind to surface with low affinity, there is also micelle formation competing for surface adsorption. Thus, the lowest size was found in the $f 7$ i.e., $174.8 \pm 24.3 \mathrm{~nm}$.

\section{Table-7: Experiment -IV: PVP formulations}

Particle size of all formulations was found in the nanometer range. The results of particle size data are shown in Table-7.

\begin{tabular}{lllll}
\hline Particle size & \multicolumn{3}{l}{ Molar ratio } \\
\cline { 2 - 5 } & $\mathbf{1 : 0 . 5 [ F 9 ]}$ & $\mathbf{1 : 1 [ F 1 0 ]}$ & $\mathbf{1 : 3 [ F 1 1 ] ~}$ & $\mathbf{1 : 6 [ F 1 2 ]}$ \\
\hline D $_{10}$ & 269.5 & 106.9 & 133.8 & 121.7 \\
D50 $_{50}$ & 274.2 & 166.5 & 171.6 & 151.3 \\
D90 & 544.4 & 270.1 & 154.2 & 160.5 \\
Mean Diameter & $\mathbf{3 6 2 . 7 n m}$ & $\mathbf{1 6 1 n m}$ & $\mathbf{1 5 3 . 2 n m}$ & $\mathbf{1 4 4 . 5 n m}$ \\
PDI & $\mathbf{0 . 7 8 5}$ & $\mathbf{0 . 5 9 3}$ & $\mathbf{0 . 4 6 9}$ & $\mathbf{0 . 4 5 4}$ \\
\hline
\end{tabular}

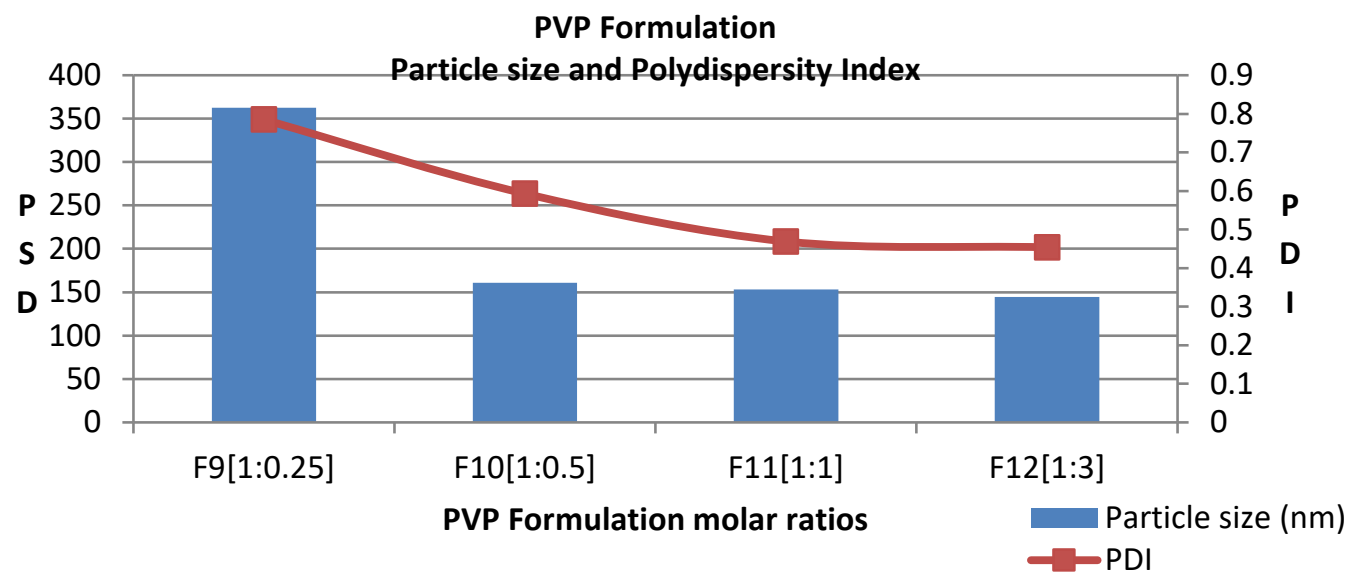

Fig. 12: PVP Formulations Particle size (nm) and Polydisperisty index

Conclusion: All the formulations consists of nanosized paricles, the average size and polydispersity index of nanocrystals were given in tha table. The size of docetaxel nanocrystals in this study were ranged between 362.7 to $144.5 \pm 62.9 \mathrm{~nm}$.the particle size of four molar ratios found to be in the fallowing order: F9 [1:0.5] >F10 [1:1]> F11 [1:3]> F12 [1:6]. From f9 to f10 there was a greater decrease in particle size but in case of $\mathrm{f} 11$ and $\mathrm{f} 12$ it was a slight decrese in paricle size and the size was almost nearer to the $\mathrm{f} 10$ formulation. From this observation, it can be concluded that after 1:1 molar ratio, upon increasing the PVP concentration there was no greater decrease in the particle size so, there was no use of further increasing stabilizer concentration. 


\section{Table-8: Experiment -V: Tween 80 and PLGA formulations}

Particle size of the formulation was found in the nanometer range. The results of particle size data are shown in Table-8.

\begin{tabular}{ll}
\hline \multirow{2}{*}{ Particle size } & Molar ratio \\
\cline { 2 - 2 } & $\mathbf{1 : 1 : 0 . 0 0 1}[\mathrm{F13}]$ \\
\hline $\mathrm{D}_{10}$ & 29.3 \\
$\mathrm{D}_{50}$ & 58.6 \\
$\mathrm{D}_{90}$ & 170.9 \\
Mean Diameter & $\mathbf{8 1 . 0 \mathbf { n m }}$ \\
PDI & $\mathbf{0 . 7 2 6}$ \\
\hline
\end{tabular}

Conclusion: The particle size and poly dispersity index of PLGA nanocrystals was given in the table. In case of tween 80- 1:1 formulation the particle size was found to be $142.9 \mathrm{~nm}$. This size was still reduced to $81 \pm 61.2 \mathrm{~nm}$ with the addition PLGA to the formulation this is due to, PLGA provides the additional effect to the surfactant by reducing the particle reagregation by impating the viscosity to the formulation.

\section{ZETAPOTENTIAL}

Zeta potential of all formulations was found in the in the range of -18.17 to $-34.60 \mathrm{mV}$. The results of Zeta potential data are shown in Table-9 in Fig.13.

Table-9: Zeta potential Data for All formulations

\begin{tabular}{llll}
\hline Experiment number & Formulation code & Molar ratio & zetapotential \\
\hline & F1 & $1: 0.5$ & -30.2 \\
II & F2 & $1: 1$ & -31.8 \\
& F3 & $1: 3$ & -24.5 \\
& F4 & $1: 6$ & -18.7 \\
& F5 & $1: 0.5$ & -31.5 \\
III & F6 & $1: 1$ & -32.6 \\
& F7 & $1: 3$ & -34.6 \\
& F8 & $1: 6$ & -28.3 \\
& F9 & $1: 0.5$ & -19.8 \\
IV & F10 & $1: 1$ & -29.4 \\
& F11 & $1: 3$ & -22.6 \\
V & F12 & $1: 6$ & -23.8 \\
\hline
\end{tabular}

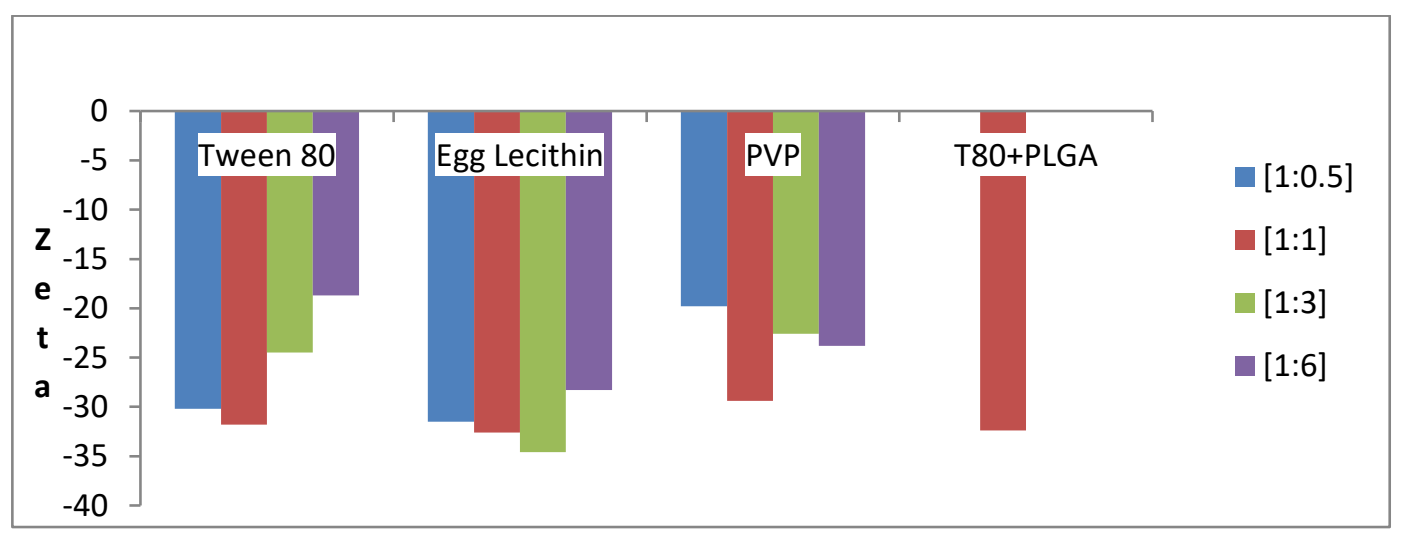

Fig. 13: Zeta Potential for All formulations 
Conclusion: The stability study of the nanocrystals was evaluated by measuring the zeta potential of the nanocrystals by the zeta meter. The results are evaluated in Table. Zeta potential of all formulated nanocrystals was in the range of -18.17 to -34.60
mV.which indicates moderate stability with no agglomeration.

Based on the particle size, ploy dispersity index and zeta potential values the four formulations from total of thirteen formulations were selected as optimized formulations.

\section{INVITRO RELEASE PROFILE OF DOCETAXEL NANOCRYSTAL FORMULATIONS FOR PARENTERAL ADMINISTRATION:}

1.1. Optimization of dissolution media

\begin{tabular}{lllll}
\hline Parameter & Qty of drug & Volume of Buffer & Abs & Concentration [mg/mL $]$ \\
\hline PBS 7.4 & $20 \mathrm{mg}$ & $50 \mathrm{~mL}$ & 0.02 & 0.01 \\
PBS 7.4+ 1\% Tween 80 & $20 \mathrm{mg}$ & $50 \mathrm{~mL}$ & 0.11 & 0.03 \\
PBS 7.4 + 2\%Tween 80 & $20 \mathrm{mg}$ & $50 \mathrm{~mL}$ & 0.195 & 0.08 \\
PBS 7.4+ 4\% Tween 80 & $20 \mathrm{mg}$ & $50 \mathrm{~mL}$ & 0.42 & 0.14 \\
PBS 7.4 +6\%Tween 80 & $20 \mathrm{mg}$ & $50 \mathrm{~mL}$ & 0.75 & 0.25 \\
\hline
\end{tabular}

The saturation solubility of Docetaxel in PBS7.4 with $6 \%$ Tween 80 found to be $0.25 \mathrm{mg} / \mathrm{mL}$, thus $600 \mathrm{~mL}$ of Buffer will provide the required sink condition of $\geq 3$.

\subsection{Release Profile and Kinetics}

Table -10: Zero order release profile of optimized formulations:

\begin{tabular}{lllll}
\hline \multirow{2}{*}{ Time in hours } & \multicolumn{4}{l}{ Cumulative \% drug release } \\
\cline { 2 - 5 } & Tween 80[F2] & Egg lecithin[F7] & PVP[F10] & PLGA[F13] \\
\hline $\mathbf{0}$ & $\mathbf{0}$ & $\mathbf{0}$ & $\mathbf{0}$ & $\mathbf{0}$ \\
24 & 31.216 & 43.138 & 47.665 & 5.82 \\
48 & 50.158 & 59.562 & 64.766 & 16.252 \\
72 & 74.523 & 70.454 & 81.216 & 29.684 \\
96 & 100 & 84.312 & 90.213 & 51.799 \\
120 & -- & -- & -- & 66.753 \\
144 & -- & -- & -- & 80.408 \\
168 & -- & -- & -- & 97.987 \\
\hline
\end{tabular}

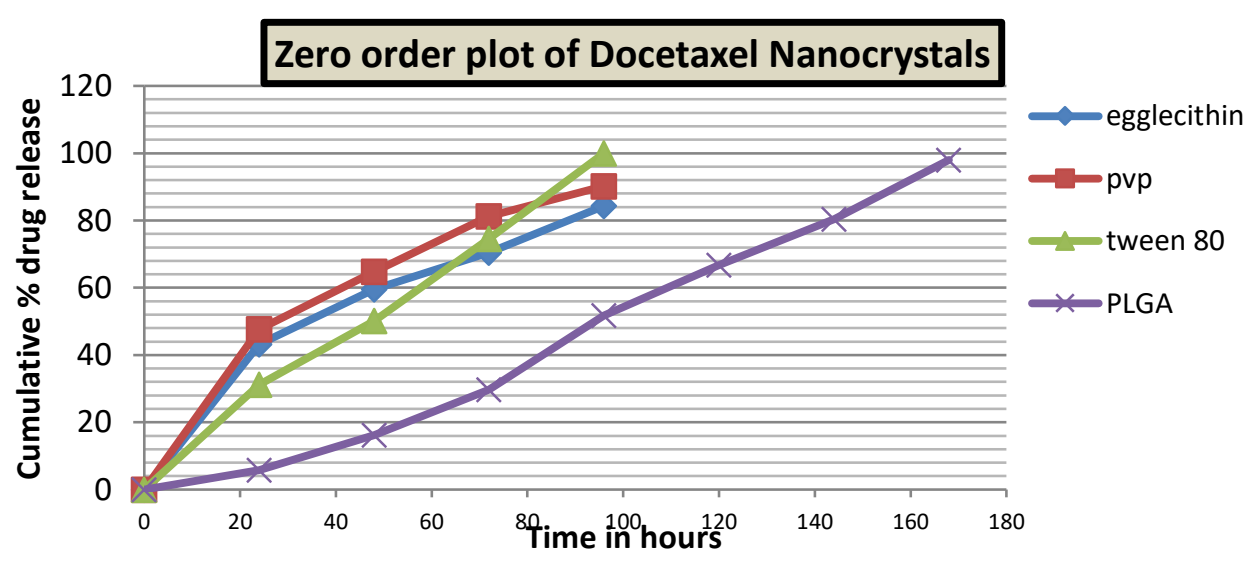

Fig. 14: Invitro release profile of Zero order release kinetics

Table -11: First order release profile of optimized formulations: 


\begin{tabular}{lllll}
\hline \multirow{2}{*}{ Time in hours } & \multicolumn{4}{l}{ Log Cumulative \% drug remain release } \\
\cline { 2 - 5 } & Tween 80[F2] & Egg lecithin[F7] & PVP[F10] & PLGA[F13] \\
\hline $\mathbf{0}$ & 2 & 2 & 2 & 2 \\
24 & 1.837487 & 1.754822131 & 1.718792 & 1.973959 \\
48 & 1.697595 & 1.606789668 & 1.546962 & 1.922974 \\
72 & 1.406148 & 1.470498693 & 1.273788 & 1.847054 \\
96 & -- & 1.1955675 & 0.990649 & 1.683056 \\
120 & -- & -- & -- & 1.521752 \\
144 & -- & -- & -- & 1.292079 \\
168 & -- & -- & -- & 0.303843 \\
\hline
\end{tabular}

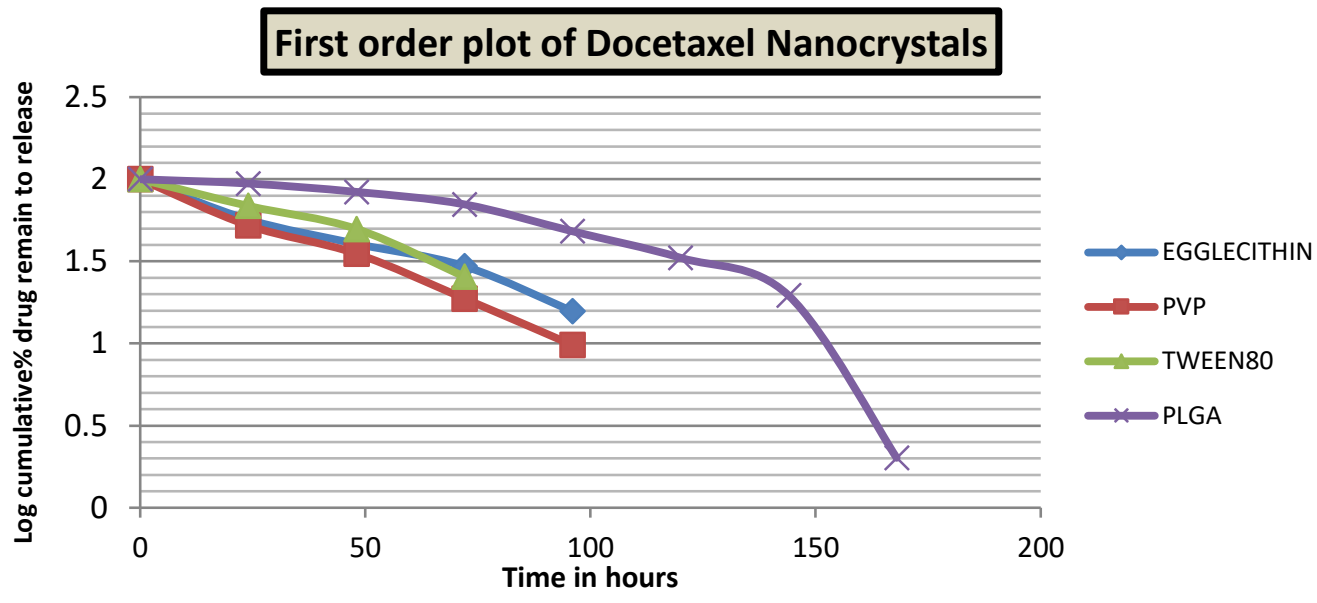

Fig. 15: Invitro release profile of First order release kinetics

Table no. 12: Higuchi release profile of optimized formulations:

\begin{tabular}{|c|c|c|c|c|}
\hline \multirow[b]{2}{*}{ VT } & \multicolumn{4}{|c|}{ Cumulative \% drug release } \\
\hline & Tween 80[F2] & Egg lecithin[F7] & PVP[F10] & PLGA[F13] \\
\hline 0 & 0 & 0 & 0 & 0 \\
\hline 4.898979 & 31.216 & 43.138 & 47.665 & 5.82 \\
\hline 6.928203 & 50.158 & 59.562 & 64.766 & 16.252 \\
\hline 8.485281 & 74.523 & 70.454 & 81.216 & 29.684 \\
\hline 9.797959 & 100 & 84.312 & 90.213 & 51.799 \\
\hline 10.95445 & -- & -- & -- & 66.753 \\
\hline 12.00 & -- & -- & -- & 80.408 \\
\hline 12.96148 & -- & -- & -- & 97.987 \\
\hline
\end{tabular}




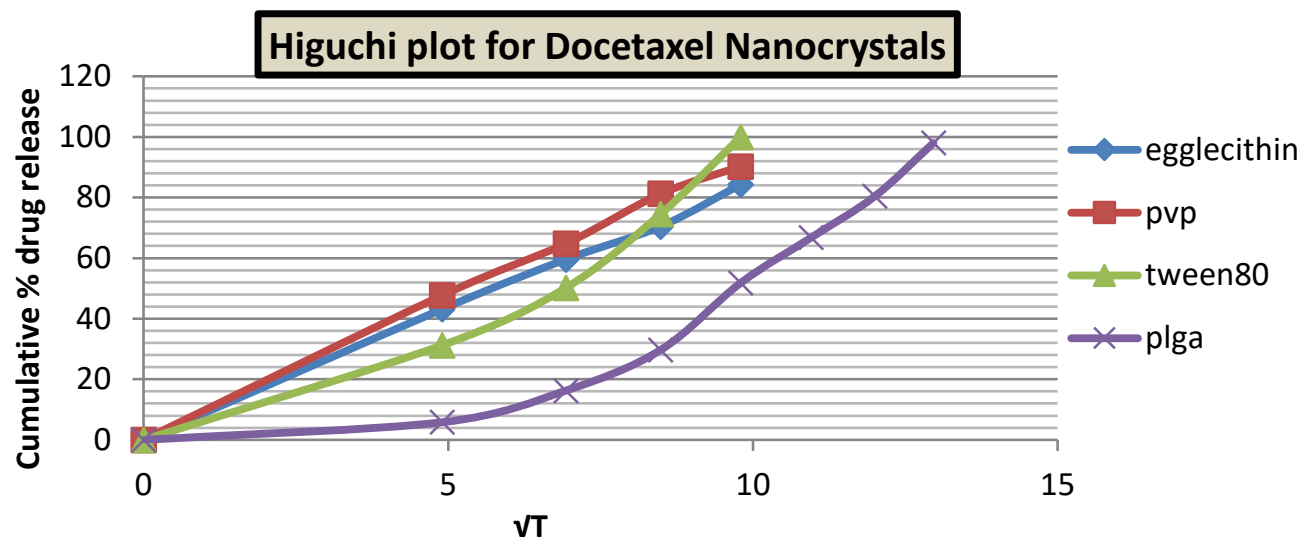

Fig. 16: Invitro release profile of Higuchi release kinetics

Table -13: Korsmeyer-peppas release profile of optimized formulations:

\begin{tabular}{lllll}
\hline \multirow{2}{*}{ Log time } & \multicolumn{4}{l}{ Log Cumulative \% drug release } \\
\cline { 2 - 5 } & Tween 80[F2] & Egg lecithin[F7] & PVP[F10] & PLGA[F13] \\
\hline $\mathbf{0}$ & $\mathbf{0}$ & $\mathbf{0}$ & $\mathbf{0}$ & $\mathbf{0}$ \\
1.380211 & 1.494377 & 1.63486001 & 1.6781996 & 0.764923 \\
1.681241 & 1.70034 & 1.77496927 & 1.81134708 & 1.210907 \\
1.857332 & 1.87229 & 1.84790566 & 1.9096416 & 1.472522 \\
1.982271 & 2 & 1.92588939 & 1.95526912 & 1.714321 \\
2.079181 & -- & -- & -- & 1.824471 \\
2.158362 & -- & -- & -- & 1.905299 \\
2.225309 & -- & -- & -- & 1.991168 \\
\hline
\end{tabular}

korsmeyer-peppas plot for Docetaxel Nanocrystals

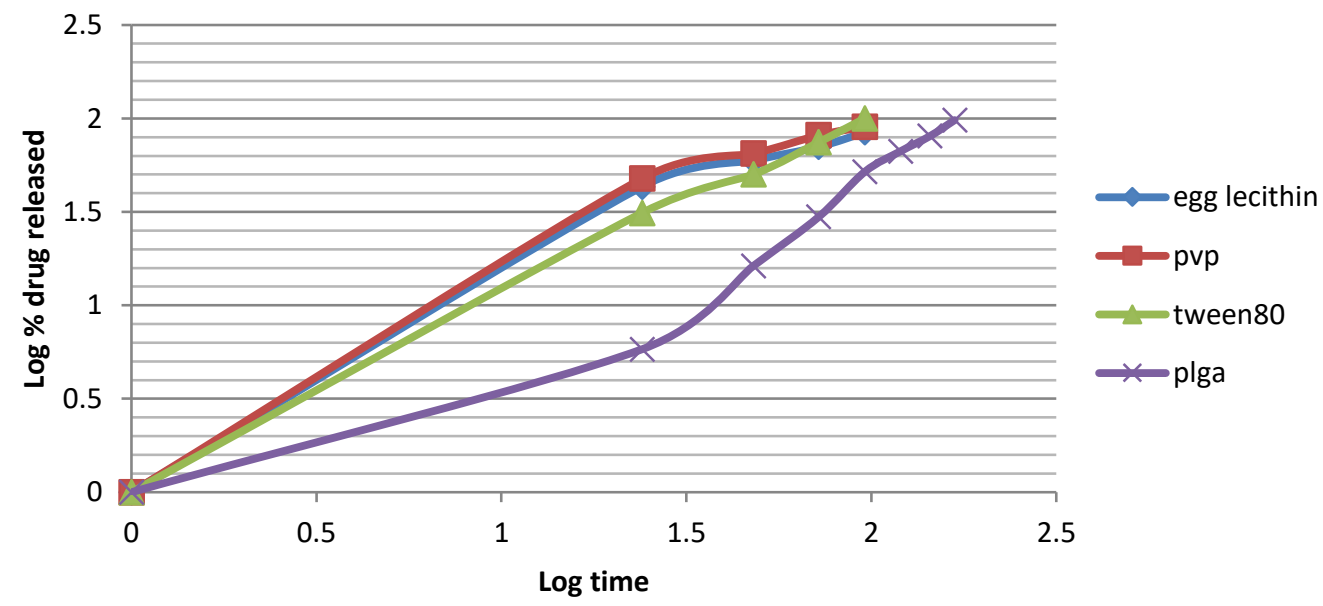

Fig.17: Invitro release profile of Korsmeyer-peppas release kinetics 


\section{REGRESSION COEFFECIENT AND DIFFUSION COEFFECIENT VALUES OBSERVED IN VARIOUS KINETIC MODELS FOR FOUR FORMULATIONS OF DOCETAXEL NANOCRYSTALS:}

\begin{tabular}{lllllc}
\hline \multirow{2}{*}{ FORMULATION } & ZERO ORDER & FIRST ORDER & HIGUCHI & \multicolumn{2}{l}{ KORSMEYER PEPPAS } \\
\cline { 2 - 6 } & $\mathbf{R}^{\mathbf{2}}$ & $\mathbf{R}^{\mathbf{2}}$ & $\mathbf{R}^{\mathbf{2}}$ & $\mathbf{R}^{\mathbf{2}}$ & $\mathbf{n}$ \\
\hline Tween80[F2] & 0.993 & 0.970 & 0.924 & 0.996 & 1.020 \\
Egg lecithin[F7] & 0.849 & 0.984 & 0.998 & 0.975 & 1.031 \\
PVP[F10] & 0.836 & 0.994 & 0.998 & 0.973 & 1.055 \\
PLGA[F13] & 0.968 & 0.735 & 0.767 & 0.929 & 0.827 \\
\hline
\end{tabular}

In-vitro release data obtained for optimized formulations F2, F7, F9 and F13 are tabulated in Table no. respectively with their corresponding plots. Cumulative percentage drug released for F2 after 96 hours was more i.e., $100 \%$, followed by F10 was $90.213 \%$ and for F7 was $84.312 \%$. Where as in case of F13 the cumulative percentage drug released after 96 hours was only 51.799 and reached $97.987 \%$ after 168 hours. It was evident that the drug release from the F13 formulation decreased compared with the other three formulations. It was suggesting that the presence of polymer sustained the drug release. The formulations F2, F7 and F9 showed a biphasic release with initial burst effect. The mechanism for the burst release can be attributed to the sudden exposure of nanocrystal surface to the PBS. By this one can conclude that the dissolution rate was enhanced by nanocrystal formulations. But the presence of polymer layer around the particle avoid the sudden exposure of particle surface to the surrounding medium there by expect a slow drug release. Calculated regression co-efficient and diffusion co-efficient values for four formulations were tabulated in Table. Plots of zero order, first order, Higuchi and Peppa's were depicted in Fig. These values were compared with each other for model and drug equation. Based on highest regression $\left[r^{2}\right]$ values, the best-fit model for F2 and F 13 was zero order and for F7 and F10 was Higuchi diffusion model. All the formulations were then fitted into Korsmeyer-peppas model and $n$ values were reported. For F2, F7 and F10 it was $>1$ indicates Supercase-II transport and for F13 it was $<0.89$ indicates non-fickian diffusion.

\section{CONCLUSION:}

Cancer is the end product of a multi-step process that occurs over many years. "Cancer refers to any one of a large number of diseases characterized by the development of abnormal cells that divide uncontrollably and have the ability to infiltrate and destroy normal body tissue". The Drug delivery remains a challenge in management of cancer. Cancer drug delivery is no longer simply wrapping up cancer drugs in a new formulation for different routes of delivery. The focus is on targeted cancer therapy. The newer approaches to cancer treatment not only supplement the conventional chemotherapy and radiotherapy but also prevent the damage to normal tissues and prevent drug resistance. Nanoparticles have been used in vivo to protect the drug entity in the systemic circulation, restrict access of the drug to the chosen sites and to deliver the drug at a controlled and sustained rate to the site of action. Various polymers have been used in the formulation of nanoparticles for drug delivery to increase therapeutic benefit while minimizing side effects. Recently there has been immense interest in nanocrystal technology. nanocrystallization is a technique to produce crystalline particles of poorly soluble drugs in the nanometer range (i.e.,nanocrystals). Due to the size and, thus, the high surface area to volume ratio, nanocrystals can increase the saturation solubility of a drug and the dissolution rate of drug particles. Nanocrystals have gained increasing interest in the pharmaceutical industry because of the simple structures, compositions and controlled release affords less frequent administration, thereby increasing patient compliance, reducing discomfort, protecting the therapeutic compound and maintaining constant blood levels of the drug within body. Docetaxel is presently marketed as TAXOTERE.RTM. injection concentrate by Aventis Pharmaceutical (Bridgewater, N.J.). Because of poor water solubility docetaxel is given in a vehicle containing high concentration of tween 80 \& the 
injection need to be diluted with $13 \%$ ethanol in water for injection. The presence of tween 80 \& ethanol cause severe adverse effects like several hypersensitivity reactions also incompatibility with common PVC intravenous administration sets. Hypersensitivity symptoms associated with docetaxel include hypotension, bronchospasm and generalized rash / erethma in addition to bone marrow suppression, peripheral neurotoxicity and mucositis. Nanocrystals have been used in vivo to protect the drug entity in the systemic circulation, restrict access of the drug to the chosen sites and to deliver the drug at a controlled and sustained rate to the site of action. Various polymers have been used in the formulation of nanocrystals for drug delivery research to increase therapeutic benefit, while minimizing side effects. Most of the nanocrystals are taken up from blood by macrophages of reticuloendithelial system; therefore, nanocrystals can provide an effective strategy in controlled drug delivery for concentration of docetaxel in liver, lungs, spleen, kidney and small intestine. Docetaxel nanocrystals were prepared by using nanoprecipitation method using different types of stabilizers and polymers. Total sixteen formulations were prepared and labeled as F1, F2, F3....F16 by changing concentration of stabilizers and polymer. The stabilizers used are tween 80, Egg lecithin and PVP and the polymer used is PLGA. The preformulation studies were performed with pure drug and excipients and the prepared formulations were evaluated for parameters like particle size, zeta potential, scanning electron microscopy, assay, invitro drug release, dilution compatibility, syringeability and injectability, stability testing and others. Preformulation studies revealed that the docetaxel and PVP were compatible without any significant changes in the chemical nature of the docetaxel. Based on the particle size distribution, PDI and Zeta potential values four formulations were selected as best formulations and those four formulations were evaluated for further parameters. Particle size of the Docetaxel nanocrystals revealed that the all formulations were found in nanometer range and the Zeta potential was in the acceptable limit. The amount of \% drug content in docetaxel nanocrystals was found to be $100 \%, 102.12 \%$, 99.562\% and $103.25 \%$ respectively for formulations $F-2$, F-7, F-10 \& F-13. All the formulations were stable up to
8 hours upon dilution and all formulations were passed freely from five different needle sizes. In-vitro release study was analyzed using various mathematical models. Cumulative percentage drug released for F2 after 96 hours was more i.e., 100\%, followed by F10 was $90.213 \%$ and for F7 was $84.312 \%$. Where as in case of F13 the cumulative percentage drug released after 96 hours was only 51.799 and reached $97.987 \%$ after 168 hours. It was evident that the drug release from the F13 formulation decreased compared with the other three formulations. It was suggesting that the presence of polymer sustained the drug release. Based on highest regression $\left[r^{2}\right]$ values, the best-fit model for $F 2$ and $F 13$ was zero order and for F7 and F10 was higuchi diffusion model. All the formulations were then fitted into korsmeyer-peppas model and $\mathrm{n}$ values were reported. For F2, F7 and F10 it was $>1$ indicates supercase-II transport and for F13 it was $<0.89$ indicates Non-Fickian diffusion. Parenteral nanocrystal optimized formulations were kept at accelerated stability. It was observed that there was no change in the physical appearance of the formulation. The physical appearance of the formulation remained clear and colorless solution at the end of stability. $\mathrm{pH}$ of the formulation remained unchanged during stability.

\section{REFERENCES}

1. Formulation and evaluation of liposomal drug delivery system for an anticancer drug and the Study the effect of various stabilizers based on physiochemical and in vitro characterization. Ganesh g. N. K, gowthamarajan k, suresh kumar $r$,Senthil $v$, jawahar $n$, venkatesh $n$, manjusha. $P$, department of pharmaceutics, j. S. S. College of pharmacy,Tamilnadu, india. IJPRD, 2011; Vol 3(3): May 2011 (27 -37).

2. Understanding the structure and stability of paclitaxel nanocrystals. Jiexin Deng, Leaf Huang, Feng Liu. International Journal of Pharmaceutics 390 (2010) 242249.

3. Docetaxel-loaded solid lipid nanoparticles: Preparation, characterization, in vitro, and in vivo evaluations. Navid Mosallaei, Mahmoud Reza Jaafari, Mohammad Yahya Hanafi-Bojd, Shiva Golmohammadzadeh, Bizhan Malaekeh-Nikouei, American Pharmacists Association J Pharm Sci 102:1994-2004, 2013.

4. Preparation And Characterization Of Simvastatin Nanosuspension By Homogenization Method, Athul P.V. Nandha College Of Pharmacy And Research Institute, 
Erode 52, India. International Journal of PharmTech Research CODEN (USA): IJPRIF ISSN: 0974-4304, Vol.5, No.1, pp 193-197, Jan-Mar 2013.

5. Kinetic modeling on drug release from controlled drug delivery systems, Suvakanta dash1, padala narasimha murthy, lilakanta nath and prasanta chowdhury girijananda chowdhury institute of pharmaceutical science, Azara, hathkhowapara, nh-37, guwahati, assam, 781017 india. Acta Poloniae Pharmaceutica ñ Drug Research, Vol. 67 No. 3 pp. 217 n 23, 2010.

6. Evaluation of drug release kinetics from ibuprofen matrix tablets using hpmc M. Harris shoaib, jaweria tazeen, hamid a. Merchant And rabia ismail yousuf. Department of pharmaceutics, faculty of pharmacy, university of karachi, Karachi-75270, Pakistan. Pak. J. Pharm. Sci., 2006, Vol.19 (2), 119-124

7. Nanoparticles - A Revie, VJ Mohanraj1 and Y Chen, Orchid Chemicals \& Pharmaceuticals Limited, Chennai, India School of Pharmacy, Curtin University of Technology, Perth, Australia. Tropical Journal of Pharmaceutical Research, June 2006; 5 (1): 561-573.

8. Targeting cancer cells using PLGA nanoparticles surface modified with monoclonal antibody, Petra Kocbek, Natasa Obermajer, Mateja Cegnar, Janko Kos, Julijana Kristl.

9. Drug nanocrystals: A novel formulation approach for poorly Soluble drugs, Suman katteboinaa1, v s r chandrasekhar. P, balaji. S, department of pharmaceutics, bapatla college of pharmacy, bapatla, guntur dist, Andhra pradesh, india - 522101. International Journal of PharmTech Research CODEN(USA): IJPRIF ISSN : 09744304 Vol.1, No.3, pp 682-694, July-Sept 2009.

10. A review on drug nanocrystal a carrier free drug delivery, patel.anita p, patel j.k., patel kishubu s., Nootan Pharmacy College, Visnagar-384315, Gujarat, India.IJRAP 2011, 2(2) 448-458.

11. Amidon GL,Lennemas H, Shah VP,Crison JR. A Theoretical basis for biopharmaceutic drug classification: the correlation of the in vitro drug product dissolution and invivo bioavailability. Pharm Res. 1995; 12: 413-420.

12. Lennernas $H$, Abrahamson B. The use of the biopharmaceutics classification in drug discovery and development: Current status and future extension. In drug bioavailability, estimation of solubility, permeability, absorption and bioavalability. J Pharm Pharmacol.2005; 57:273-285.

13. Mohanraj VJ, Chen Y. Nanoparticles - A Review. Trop J Pharm Res 2006;5(1):561-3.

14. Mu L, Feng SS. A novel controlled release formulation for the anticancer drug paclitaxel (Taxol)): PLGA nanoparticles containing vitamin E TPGS. J control release 2003; 86:3348.
15. Magharla DD, Rajagopalan R, Devrajan S, Rajadas J, Vamsadhara C. Biodegradation and biocompatibility of contraceptive-steroid-loaded poly (DL- lactide-coglycolide) injectable microspheres: in vitro and in vivo study.Contraception. 2006; 74:148-56.

16. Berkland C, king M, Cox A, Kim K, Pack DW. Precise control of PLG microspheres size provides enhanced control of drug release rate. J Control Release. 2002; 82:137-47.

17. Preparation and antitumor study of camptothecin nanocrystals, Hua Zhanga, Christin P. Hollis, Qiang Zhanga, Tonglei Li, International Journal of Pharmaceutics 415 (2011) 293-300.

18. Development of a chemically stable 10hydroxycamptothecin nanosuspensions, Xiaohui Pua, Jin Suna, YanWang, International Journal of Pharmaceutics 379 (2009) 167-173.

19. Zhang, X., Xia, Q., Gu, N., 2006b. Preparation of all-trans retinoic acid nanosuspensions using a modified precipitation method. Drug Dev. Ind. Pharm. 32, 857-863.

20. Muller, R.H., Peters, K., Becker, R., Kruss, B., 1995a. Nanosuspensions-a novel formulation for the i.v. administration of poorly soluble drugs. In: 7th Int. Conf. on Pharm. Technol. (APV:APGI), Budapest, pp. 491-492.

21. Peters, K., Leitzke, S., Diederichs, J.E., Borner, K., Hahn, H., Müller, R.H., Ehlers, S., 2000. Preparation of clofazamine nanosuspension for intravenous use and evaluation of its therapeutic efficacy in Mycobacterium avium infection. J. Antimicrob. Chem.45, 77-83.

22. Phanchaxari Dandagi. M., Sumit Kaushik., Shaktish Telsang., Enhancement of solubility and dissolution property of Griseofulvin by nanocrystallization, Int. J. Drug Dev. \& Res, 3(2), 2010, 180-191.

23. Suvakanta Dashl., Padala Narasimha Murthy., LilakantaNath., Prasanta Chowdhury., Kinetic modeling on drug release from controlled drug delivery systems, Acta Poloniae Pharmaceutica-Drug Research, 67(3), 2010, 217 223.

24. Yuan Gao., Jianjun Zhang., Huixia Lv., Kun Jiang., Enhanced bioavailability after oral and pulmonary administration of Baicalein nanocrystal, Int. J. Pharm, 420, 2011,180-188.

25. Dianrui Zhang., Guangpu Liu., Yang Jia., Dandan Zheng., Yue Liu., Cunxian Duan., Lejiao Jia., Qiang Zhang., Hongxiang Lou., Comparison of different methods for preparation of a stable riccardin $\mathrm{D}$ formulation via nanotechnology, Int. J. Pharm, 422, 2012, 516-522.

26. Peng Liu., Xinyu Rong., Johanna Laru., Bert van Veen., Juha Kiesvaara., Jouni Hirvonen., Timo Laaksonen., Leena Peltonen., Nanosuspensions of poorly soluble drugs: Preparationand development by wet milling, Int. J. Pharm, 411, 2011, 215-222. 
27. Patravale VB, Date AA, Kulkarni RM. Nanosuspensions: a promising drug delivery strategy. J Pharm Pharmacol. 2004;56 (7):827-40.

28. Li X, Gu L, Xu Y, Wang Y. Preparation of fenofibrate nanosuspension and study of its pharmacokinetic behavior in rats. Drug Dev Ind Pharm. 2009;35(7):827-33.

29. Mishra PR, Al Shaal L, Muller RH, Keck CM. Production and characterization of Hesperetin nanosuspensions for dermal delivery. Int J Pharm. 2009;371(1-2):182-9.

30. Muller RH, Jacobs C, Kayser O. Nanosuspensions as particulate drug formulations in therapy. Rationale for development and what we can expect for the future. Adv Drug Deliv Rev. 2001;47 (1):3-19.

31. Muller RH, Peters K. Nanosuspensions for the formulation of poorly soluble drugs I. Preparation by a size-reduction technique. Int J Pharm. 1998; 160:229-37.

32. Wang L, Cui FD, Sunada H. Preparation and evaluation of solid dispersions of nitrendipine prepared with fine silica particles using the melt-mixing method. Chem Pharm Bull. 2006;54(1):37-43. 1142 Quan et al.
33. Docetaxel-loaded liposomes: preparation, pH sensitivity, Pharmacokinetics, and tissue distribution, Hong zhang, Rui-ying L, Journal of Zhejiang University-SCIENCE B (Biomedicine \& Biotechnology), Received Mar. 27, 2012; Revision accepted Nov. 11, 2012; Crosschecked Nov. 14 2012.

34. Baker, J., Ajani, J., Scotté, F., Winther, D., Martin, M., Aapro, M.S., von Minckwitz, G., 2009. Docetaxel-related side effects and their management. Eur. J. Oncol. Nurs.,13(1):49-59. [doi: 10.1016/j.ejon.2008.10.003].

35. Preparation, characterization, cytotoxicity and pharmacokinetics of liposomes containing docetaxel, Maria Laura Immordino, Paola Brusa, Journal of Controlled Release 91 (2003) 417-429.

36. T.Musumeci, C.A. Ventura, I. Giannone, B.Ruozi, L.Montenegro, R.Pignatello, G.Puglisi (2006). PLA/PLGAnanoparticles for sustained release of docetaxel, International Journal of pharmaceutics 325,172-179.
*Corresponding Author: Prasad Garrepally*

Email: garrepallyprasad@gmail.com 